\title{
High-resolution analysis of 1-day extreme precipitation in a wet area centred over eastern Liguria, Italy
}

M. Brunetti ${ }^{1}$, A. Bertolini ${ }^{1,2}$, M. Soldati ${ }^{2}$, M. Maugeri ${ }^{1,3}$

1 Institute of Atmospheric Sciences and Climate - Consiglio Nazionale delle Ricerche, ISAC-CNR, Bologna, Italy

2 Dipartimento di Scienze Chimiche e Geologiche, Università di Modena e Reggio-Emilia, Via Campi 103, 41125 Modena, Italy

3 Department of Environmental Sciences and Policy (DESP), Università degli Studi di Milano, Milan, Italy

Corresponding Author: $\quad$ Michele Brunetti

$$
\text { m.brunetti@isac.cnr.it }
$$$$
\text { Ph.: +390516399624 }
$$

Fax: +390516399658

\begin{abstract}
This study analyses 371 yearly series of 1-day precipitation maxima extracted from a data set of highquality homogenized rain gauge records covering an area of about $25000 \mathrm{~km}^{2}$ in the western part of northern-central Italy that includes eastern Liguria and northern Tuscany and is very prone to severe floods and shallow landslides.

Return levels of 1-day extreme precipitation (corresponding to 10-, 50- and 100-year return periods as predicted by a generalized extreme value distribution (GEV)) are estimated both for station sites and for the nodes of a high-resolution grid (30 arcsec). GEV parameters are estimated by regional frequency analysis using the station-year approach. Grid point index floods are estimated from yearly cumulative precipitation normals exploiting the very high correlation existing at local scale between station index flood and the corresponding yearly precipitation normals.
\end{abstract}


Results clearly show the high vulnerability of this region to extreme precipitation events and highlight the different role played by total annual precipitation normals and by both scale and shape parameters in regulating the longer period return levels.

The results presented in this paper allow better estimating the climatology of extreme events in the study area, contributing to a more effective hazard assessment at different spatial and temporal scales.

\section{Introduction}

Italy's vulnerability to extreme precipitation events is well documented. While it is partly due to overdevelopment, many areas experience extraordinary1-day precipitation maxima peaking above $300 \mathrm{~mm}$, and presenting challenges for sound management to reduce flooding and landsliding. This problem is even more relevant if we consider that extreme precipitation events in the Mediterranean are expected to increase in the future, even though models indicate a decrease of total precipitation and frequency of wet days (Giorgi and Lionello, 2008).

It is therefore very important to quantify the spatial distribution of Italian extreme precipitation events, to investigate if it has changed during the last century and to provide the scientific and nonscientific community with return level estimates for long time intervals (e.g. 100 years) produced at high spatial resolution at least for 1-day precipitation.

This work addresses these issues focusing on a small area including eastern Liguria and northern Tuscany (see Figure 1), which is very prone to severe floods and shallow landslides, especially in a period spanning from late summer (the end of August) to late fall (early December). Because of the topography, urbanized areas in this region are along the coast, often in proximity to small catchment river outlets. Therefore, severe weather events represent a serious threat, as heavy and persistent rainfall can become in a few hours devastating floods (Davolio et al., 2014; Benito and Hudson, 2010) often accompanied by severe mass wasting processes in mountain and hilly areas. A number of topographical and meteorological factors enhance flood episodes in this study area, such as the relatively steep slopes, with mountains reaching high elevations (around $2000 \mathrm{~m}$ ) within a few kilometres from the coast, a concave arc-shaped coastline, short rivers with very small catchment areas (in some cases even smaller than $10^{2} \mathrm{~km}^{2}$ ), a coastal slope exposed to moist southerly flows carrying important sensible and latent heat fluxes from the sea, and the formation of convective systems. The latter factors are in turn often associated with cyclonic disturbances propagating from 
the Atlantic to the Mediterranean or originating/reinvigorating in the area of the Gulf of Genoa and surroundings, due to orographically induced cyclogenesis (see Buzzi et al., 2014 and references therein). A particular role is played by back-building mesoscale convective systems which caused several severe floods over Liguria in the last decade (see Parodi et al., 2017 and references therein). Convective cells, embedded in such systems, are generated on the sea by the convergence of a warm and moist south-easterly flow and a northerly low-level much colder and drier one and are then advected to the land where the combined action of these currents and the topography force them to persist for several hours over a very localized area (Buzzi et al., 2014; Fiori et al., 2014; 2017; Parodi et al., 2017).

A few of the disastrous events that occurred in this area, include the flash-flood of San Fruttuoso occurring on 25 September 1915 (Faccini et al., 2009; Parodi et al., 2017), the flood in Val Trebba of 19 September 1953 (Faccini et al., 2016), the Genoa flood of 7 and 8 October 1970 (Roth et al., 1996; Siccardi, 1996), the Versilia flood of 19 June 1996 (Mazzoni et al., 1997; Cacciamani et al., 1997) the Cinque Terre and Genoa floods of 25 October and 4 November 2011 (Rebora et al., 2013; Davolio et al., 2015; Galve et al. 2015), the Genoa flood of 9 and 10 October 2014 (Faccini et al., 2016), the Chiavari flood of 10 November 2014 and the most recent Genoa flood of 23 November 2016 (see also Faccini et al., 2016, for a list of flood events caused by the Bisagno river in the past two centuries).

Several studies have attempted assessments of possible changes of precipitation extremes over the Mediterranean basin (see e.g. Brunetti et al., 2001, 2004; Alpert et al., 2002; Kostopoulou and Jones, 2005; Moberg et al., 2006; Brunet et al., 2007; Kioutsioukis et al., 2010; Rodrigo, 2010; Toreti et al., 2010, van den Besselaar et al., 2013). No coherent signals emerge throughout the whole basin (Ulbrich et al., 2012), results being dependent on the specific location and the examined period (see e.g. Brugnara et al., 2012; Brunetti et al., 2012). Also restricting the analysis to the national scale, there is no clear signal about changes in the intensity and frequency of precipitation extremes. Arnone et al. (2013) analysed the annual maxima for different durations (from $1 \mathrm{~h}$ to $24 \mathrm{~h}$ ) in precipitation extremes in Sicily to highlight any duration-dependent trend. From their findings it emerges that, even if few stations exhibited a significant trend (at a significance level $p<0.05$ ), the longer is the duration, the lower is the percentage of stations with a positive trend. In particular, no station has exhibited a positive trend in $24 \mathrm{~h}$ precipitation maxima. This result was confirmed by Maugeri et al. (2015) who homogenized and analysed a data-set of 231 records of daily precipitation series for Sicily, with average length of 56 years. They identified only $6 \%$ of the series showing trends in $24 \mathrm{~h}$ precipitation maxima, either positive or negative. The absence of a clear signal in precipitation 
extremes over Italy is confirmed also by other studies. Specifically, Crisci et al. (2002) analysed historical extreme rainfall series of 1, 3, 6, 12 and $24 \mathrm{~h}$ of duration in 81 rain gauges in Tuscany region to detect possible trends. The results highlighted that more than $80 \%$ of the stations present no trend over the 1951-1994 period, with an increasing to about 30\% of sites with significance trend (mostly positive) when the analysis is restricted to the 25 years from 1970 to 1994. Piccarreta et al. (2013) analysed daily precipitation events exceeding the 90th percentile threshold over the Basilicata region, in southern Italy. They observed a negative trend in the frequency of events above the 90th percentile over the 1951-2010 period. Moreover, their contribution to total precipitation presents no significant trend, although more than half of the stations are characterized by a negative tendency. Saidi et al. (2015) observed for 5 stations in Piedmont region, in north-western Italy, that there is no uniform trend on extreme events in the examined area, and that extreme rainfall events have risen in the last 20 years only for short durations. Kumar et al. (2013) analysed the daily precipitation series of three stations (Florence and Pisa in Tuscany, and Palermo in Sicily) over the past 120 years. They observed no significant differences in 2 nd half compared to the 1 st half of the examined period at any location.

The correct statistical framework for the analysis of precipitation extremes is extreme value theory (EVT; Coles, 2001), whose objective is to quantify the stochastic behaviour of a process at unusually large or small levels. In particular, extreme value analyses usually require estimation of the probability of events that cannot be extracted from the observed frequencies because they are more extreme than those that have already been observed, but corresponding to distribution quantiles yet potentially damaging.

Daily or sub-daily precipitation time series sufficiently long to allow the estimation of high quantiles frequencies are hardly available in practice, and we often deal with rather small data samples. Such limitation in data availability complicates the application of EVT approaches and highlights the need for efficient methods of parameters estimation with small samples (Martins and Stedinger, 2000). This is particularly true when we want to fit a generalized extreme value (GEV) distribution, where only block maxima are used (e.g. annual 1-day maxima). From this point of view, the use of peaksover-threshold approaches and, more specifically, a generalized Pareto distribution (Davison and Smith, 1990; Madsen et al., 1997a), has the advantage of including more data in the analysis. However, an additional uncertainty in the fitting procedure related to the choice of the most appropriate threshold emerges. Moreover, since precipitation events cluster in time due to persistence, the problem related to the independency of events should be solved with adequate event selection criteria (Katz et al., 2002). 
In order to overcome the problem posed by the inherent rareness of extreme events, and to avoid unreliable extrapolation when dealing with data records that are short compared to the recurrence interval of interest, regional frequency analysis (RFA) is widely employed in the estimation of the flooding potential. Indeed, advantages from regional over at-site procedures have generally emerged (Hosking and Wallis, 1988; Madsen and Rosbjerg, 1997). In RFA the fitting sample is enlarged by pooling extremes from more than one measurement site. A common practice in RFA is to rescale observational records from the gathered sites so that they show the same distributional features. The scaling factor is typically named the index flood (IF). A common choice for the IF is the site-specific sample mean of extreme data (Hosking and Wallis, 1997). One of the advantages of RFA is that it allows calculating RLs at ungauged sites, provided the corresponding IFs can be estimated. There are many variants of the RFA in the scientific literature, often in conjunction with L-moments. For instance, the station-year method performing a fit of a pooled sample of rescaled extreme data (Buishand, 1991), or the regional L-moment algorithm, proposed by Hosking and Wallis (1997), where regional EVT parameters are estimated from weighted averages of L-moment-derived station parameters across many similar sites.

Regional frequency analyses of rainfall extremes were performed in several sub-regions of Italy (Franchini and Galeati, 1994; Brath et al., 1998; D’Asaro and Grillone, 2008; Maugeri et al., 2015). In some of them a subdivision of the domain into homogeneous climatic regions has been proposed to identify areas within which the statistics of rainfall extremes for a given duration are assumed to be constant (see e.g. Brath and Castellarin, 2001). Other studies exploited the relationships found between statistics of rainfall extremes and the mean annual precipitation (Schaefer, 1990; Alila, 1999; Brath et al., 2003) and used the total annual precipitation as a surrogate of geographical location. Other works normalized all the annual maxima with an index flood and applied a RFA with an optimized pooling distance. Specifically, Cannarozzo et al. (1995) analysed yearly maxima of daily and sub-daily precipitation for Sicily region (Southern Italy) by using a RFA approach based on a hierarchical regionalization procedure which led to the estimation of a two-component (a basic component and an outlying component) extreme value distribution as defined by Rossi et al. (1984). D'Asaro and Grillone (2008), for the same region, applied a RFA to daily and sub-daily precipitation considering a GEV distribution, but using the same set of parameters for the whole region. This approach is however limited by the high spatial variability of extreme precipitation that occurs over a complex terrain as the Sicily one, as highlighted by Maugeri et al. (2015), who analysed 1-day precipitation extremes for the same region with a more sophisticated RFA approach in the stationyear variant. Specifically, they first estimated for each cell of a 30 arc-second-resolution grid the rescaled GEV parameters and then converted grid-point return levels into mm using the total annual 
precipitation to get the grid-point IFs, with total annual precipitation obtained by a local weighted linear regression between precipitation and elevation as presented in Crespi et al. (2017).

In the present work, an improved version of the approach used in Maugeri et al. (2015) is applied to the domain highlighted in figure 1. As in Maugeri et al. (2015), we do not use sub-daily data because data availability is much lower than daily data. The paper is organised in four sections. After the introduction, section 2 presents the data set, its quality check and homogenization, and a summary of the methodologies applied to the data to get the high-resolution RL estimations for each grid point of a 30-arcsec-resolution Digital Elevation Model. Section 3 presents the outcomes of the analysis and critically discusses the results. Finally, the conclusions summarize the most relevant issues and presents some remarks about potential future applications.

\section{Data processing and methods}

The data-set analysed in the present work consists of 912 daily precipitation series (Figure 1) coming from different sources: Regional Environmental Agency of Liguria (ARPA Liguria), Regional Hydrographic Service of Tuscany (SIR Toscana), Regional Environmental Agency of EmiliaRomagna (ARPAE), Regional Environmental Agency of Piedmont (ARPA Piemonte) and Regional Environmental Agency of Lombardy (ARPA Lombardia).

The data-set spans the 1916-2014 period, and most of the records derive from the rain gauge network of the former Italian Hydrographical Service, whose activity lasted until the end of the 20th century. After its closure its competences and personnel were transferred to the Italian administrative regions which continued to directly manage the station network or assigned its management to external agencies; in few cases, the network was dismissed because a regional network was already set up and no resources were available to maintain both. For this reason, a significant fraction of our records consist of data of the former Hydrographic Service updated with data coming from the new regional networks.

The change of the data source, however, often implies a station relocation and/or a change from mechanical to automatic equipment. Moreover, the rules of the former network were not always maintained by the new regional agencies: among these, the observation time at 9:00 am (CET) (with the precipitation amount assigned to the day of observation), typical of the former Hydrographic 
Service, in most cases was changed to midnight, implying a shift of 18 hours in the temporal aggregation of daily amounts.

\subsection{Data quality assessment}

The transition from the old network to the new regional ones introduced therefore potential inhomogeneities in the series that must be taken into account before analysis. However, since the analysis of extremes is very sensitive to errors in the daily data, before applying the homogenization procedure we subjected the data to a quality check procedure. It has been performed considering both the average statistic of each series, and exploiting the spatial coherence of precipitation events. The goal was to check spikes, long sequences of days without precipitation and rainy days after a period with missing data.

Spikes were checked by considering all values over $15 \mathrm{~mm}$ exceeding the daily climatological value of the 10-day period to which they belong to by at least 4 standard deviations and comparing them with the maximum values recorded in the 10 nearest stations within a 3-day window centred on the value to check. If the checked value exceeded three times the neighbouring highest maximum of more than a threshold ranging from 0 to $15 \mathrm{~mm}$ (depending on the value of the neighbouring highest maximum, to contemplate the possibility of isolated events of moderate intensity in the suspect station associated with few millilitres in the surroundings) it was eliminated.

The long sequences of data with no precipitation were checked considering all dry periods of at least 15 days. They were checked against the 10 closest stations and were eliminated if the precipitation accumulated over the examined sequence averaged over all the reference series with available data is more than $10 \mathrm{~mm}$ and is accumulated over more than 2 wet days. Besides the long dry periods, each single dry day was checked. Specifically, each dry day was classified as a false zero if all the 10 closest stations had some precipitation cumulated in the three-day period centred in the dry day and at least $1 / 3$ of them had a precipitation amount greater than their climatological mean for that day.

Finally, the precipitation events following a sequence of missing values were checked to look for non-indicated cumulative values. In particular, a precipitation event following a sequence of missing (or invalidated in the previous steps) values was classified as a non-indicated cumulated value, and then eliminated, if the following conditions were satisfied: i) at least one of the 10 closest stations showed, over the same period, a cumulative amount greater than $5 \mathrm{~mm}$ and its maximum value among the three days centred on the suspect cumulative value was at least $20 \mathrm{~mm}$ lower than the suspect cumulative value; ii) the suspect cumulative value was more than $20 \mathrm{~mm}$ greater than the maximum 
(among the reference series) cumulated precipitation over the three-day period (centred in the day in which the suspect cumulated value is located), and their ratio was greater than 2 .

All the thresholds used in the quality check were tuned so that both evident errors were identified and known correct outliers were preserved by the procedure. More details on quality checking are provided in Bertolini (2017).

2246 spikes and 2753 cumulated values were identified in the quality check procedure. They correspond, respectively, to $0.022 \%$ and $0.027 \%$ of the total available data (about 28,230 stationyears). Moreover, 172,887 zero values belonging to sequence of more than 15 days (in some cases very long sequences were identified) or to single events were eliminated, corresponding to $1.68 \%$ of the total number of data.

\subsection{Data homogenization}

After quality checking, the longest series (all those with at least 30 years of available data, plus some with lower data availability (at least 20 years) to fill some areas which were not adequately represented) were evaluated for homogeneity and, if necessary, homogenized to remove the nonclimatic signals due to stations and instruments relocation, changes in the observation rules, etc.

Homogeneity is a key issue in the analysis of precipitation data. Indeed, in the last decade, the scientific community has become aware that time series of meteorological data cannot be used for climate research without clear knowledge about the homogeneity of the data. The problem is more acute when considering daily precipitation time series. In fact, daily precipitation series can present inhomogeneities not only in total amounts, but also in the number of wet days. Inhomogeneities in the number of wet days can be caused (in the early years in particular) by rainy episodes lasting several days indicated as a single 1-day event (cumulative data) not detected by the above discussed quality check procedure, but can also depend on the threshold used to define a precipitation event: an excessively low threshold can accentuate the effect of substituting a rain gauge with a more sensitive one (or vice versa). To reduce this last problem, we discarded the events below $1 \mathrm{~mm}$ and considered them as non-rainy days. Therefore, monthly precipitation amounts and monthly number of wet days were checked separately, by means of a multiple application of the Craddock test (Craddock, 1979), which is based on the hypothesis of the constancy of precipitation or wet day ratios between paired series. The homogenization approach is the same as that discussed in Brunetti et al. (2006), but adapted to daily resolution as described in Brugnara et al. (2012). Specifically, each series was tested against the series of the 10 nearest stations. The break signals of one series against all others were 
then collected in a decision matrix and the breaks were assigned to the single series according to probability. This system avoids trend imports and an inadmissible adjustment of all series to one or a few 'homogeneous reference series'. Monthly correcting factors were estimated using the neighbouring most correlated series that resulted homogeneous for a sufficiently long sub-period centred on the break year. The factors related to a certain reference series were calculated by comparing ratios with the inhomogeneous series in a reference sub-period (typically the most recent one without inhomogeneities) and in the sub-period to be corrected. To reduce noise and to extract only the physical signal (the adjustments often follow a yearly cycle), we used at least three series (when possible) and performed a trigonometric smoothing of the correcting factors. However, when a clear yearly cycle was not evident in the adjustments, we estimated a single factor valid for all months, obtained as weighted average of the monthly values, using the ratios between monthly mean precipitation and total annual precipitation as weights. The final correcting factors were then obtained averaging the single factors relative to each reference series. The trigonometric smoothing was also necessary to extrapolate daily corrections from the monthly set of correcting factors. Series with inhomogeneities in the number of wet days were not completely discarded, but data in the problematic sub-periods were eliminated. In particularly favourable conditions, we divided the series into two homogeneous series.

This process yielded 78 homogeneouse series (one of which was divided into two series because of a problem in the number of wet days) whereas the other ones required at least one homogenization (with 2.2 homogenizations per series on average). Fifteen series required separation into two parts because of a problem in the number of wet days. The final number of series useful for the analysis of extreme events is 371 (see Figure 1).

\subsection{Analysis procedure}

The series of the data set were then used to improve the data set of Italian 1961-1990 monthly precipitation normals for the study area and the same local weighted linear regression of precipitation versus elevation used in Crespi et al. (2017) was used to get new 30 arc-second-resolution monthly climatologies. Moreover, a gridded version of the daily precipitation data-set was obtained for the 1951-2012 period by interpolating the homogenized daily precipitation series onto the same grid nodes of the climatologies, following the Di Luzio et al. (2008) procedure, after a temporal synchronization of the station series, performed as suggested in Antolini et al. (2015). For the last step of this procedure (i.e. estimating daily events once the monthly data are known) we did use the full data set, because inhomogeneities do not affect this step (being the daily values converted into 
ratios with respect to the total amount of the month they belong to). The gridded version of the data set was produced only for this period because data availability becomes lower before the 1950s and after 2012.

Yearly 1-day maxima records were then extracted for each station series. They were first subjected to trend analysis by means of the Mann-Kendall test and the last square linear regression to verify if there is any significant trend in the magnitude of extremes and to estimate trend slopes. The annual maxima series were then analysed with an improved version of the approach presented in Maugeri et al. (2015). RLs at each point of a 30 arc-second-resolution grid covering the domain in figure 1 were therefore estimated by first pooling the yearly 1-day maxima records of the neighbouring stations after rescaling each of them by means of the corresponding record median that was used as station IF, then by estimating the distributional features of the pooled rescaled data, and finally by multiplying the grid-point rescaled RLs by the grid-point IF that was obtained by means of a twostep procedure. It consists in first performing a regression between the IFs and the yearly precipitation normal of the sites close to the grid point (using the station values within a search radius about the grid point ranging from 10 to $25 \mathrm{~km}$, until at least seven stations were included) and in using then the coefficients of this regression to get the grid-point IF from the corresponding yearly precipitation normal obtained from the high-resolution climatology.

The improvements with respect to the Maugeri et al. (2015) approach consist in the introduction of a site-specific estimation of the pooling radius (both maximum pooling radius and minimum pooling distance, the latter imposed to take into account the fact that stations which are too close each other are not independent) obtained with a leave-one-out approach that minimizes the differences between the single station GEV parameters and the pooled station ones. Moreover, here the same EVT approach, but without any RFA, is applied to the gridded version of the daily precipitation data.

All the parameters used within this procedure (i.e. minimum and maximum pooling radius) have been tuned minimising the errors at station sites, with the errors estimated with the leave-one-out approach.

\section{Results and Discussion}

\subsection{Precipitation regime in the study area}

Before focusing on the main results of our research, we present some preliminary analyses in order to show the spatial distribution of yearly average precipitation across the study area, to highlight the 
spatial distribution of 1-day values for some well-known high-impact events that happened in the past, and to give evidence of the absolute 1-day maxima at each station/grid-point.

Figure 1 shows the 1961-1990 climatology of yearly precipitation over the study area. As in Crespi et al. (2017), we focus on this period because it has best data availability. The average yearly precipitation over the entire area in figure 1 is $1160 \mathrm{~mm}$, however there are very strong spatial gradients with values ranging from less than $700 \mathrm{~mm}$ to over $3000 \mathrm{~mm}$. The highest values are found in the Apuan Alps, which is among the wettest areas of Italy. Rather high values are present also in many other parts of the Apennines facing Ligurian and Tyrrhenian seas.

Figure 2 shows the stations and gridded precipitation for the events listed in the introduction that fall within the period covered by the daily precipitation grid (panels a-e) together with the absolute 1-day maxima at each station and grid point (panel f). We emphasize that station values in panel $\mathrm{f}$ are not completely comparable because the station records do generally not cover the same period. However, they give a preliminary picture of the areas most subjected to severe events. We also underline that, even though extreme precipitation events in the investigated region concern usually a period that is significantly lower than 24 hours, the measuring interval ( 9 a.m. -9 a.m). is sometimes not adequate to fully capture an event that is, in some cases, splitted into two consecutive daily observations. This is clearly evident for the September 1953 and October 1970 events (in these cases we represent therefore in figure $2 \mathrm{a}$ and $2 \mathrm{~b}$ the cumulated precipitation over two consecutive days), however also for other events we have lower values than those concerning the 24-hour period with the highest precipitation. The latter variable can be obtained only with sub-daily observations, however fewer stations and a shorter period are available than 1-day precipitation data. All the events in figures 2ae give evidence that the highest precipitation values affect rather small spatial areas: this is a typical feature of the extreme events in the investigated period. The highest values are indeed those concerning the well-known October 1970 Genoa event (Roth et al., 1996; Siccardi, 1996) (this event is the highest one even if the two days are considered separately), however also other events have remarkable 1-day amounts. A clear picture of the intensity of extreme events that affected this area in the past decades is provided in Figure 2f, which shows how 1-day absolute maxima over $300 \mathrm{~mm}$ have been recorded in a significant number of stations. Grid-cell maxima are naturally slightly lower than station maxima as the gridding procedure introduces some smoothing and the underestimation/overestimation of high/low events is an intrinsic bias of any interpolation technique. Indeed, grid-cell values are a sort of areal averages, which have, as a consequence, lower absolute maxima than punctual measures. However, also for the gridded dataset, there is a significant fraction of cases with 1-day maximum over $300 \mathrm{~mm}$, especially in the Apennine areas north to Genoa, where 
there are also a few grid-points with maxima over $400 \mathrm{~mm}$ of 1-day precipitation. The very high values in figure $2 \mathrm{f}$ for the Apennine area north to Genoa are indeed due to the October 1970 event. However, also removing this event from the data set, this area still presents a significant fraction of grid points higher than $300 \mathrm{~mm}$, up to about $350 \mathrm{~mm}$.

\subsection{Extreme value analysis}

\subsubsection{1-day annual maxima trend analysis}

The first goal of the analyses we performed was to investigate whether the 1-day yearly maxima records exhibit significant trend. Specifically, we have evaluated the presence and the significance of trends in the annual maxima for our case study region, both considering the whole available period (1916-2014) and the sub-period with the highest data availability (1951-2012). In both cases, the Mann-Kendall test highlighted a low fraction of series with significant trend, 6.5\% (4\% positive and $2.5 \%$ negative) and 3\% (about $1.5 \%$ positive and $1.5 \%$ negative) for the two periods respectively (see Figure 3). Our results confirm therefore the results presented by other authors for Italy and we can conclude that also in the study region yearly 1-day maxima records do not give evidence of any significant trend. It is also worth noticing that a recent study on precipitation output from 12-km horizontal grid spacing EXPRESS-Hydro simulations of past and future climate applied to an area including the points with highest values in figure $2 \mathrm{f}$ gives evidence that peak three-hourly rainfall does not increase form 1979-2005 to 2023-2049 periods, even if future events are expected to have a larger areal coverage and a longer duration (Gallus et al., 2017).

\subsubsection{Regional frequency analysis}

The absence of significant trends in the 1-day records allows applying GEV analyses under the assumption of stationarity. We applied therefore our analysis over the entire data set without focusing on specific time windows.

GEV was applied with the RFA approach. All yearly 1-day maxima station records were first rescaled by means of their medians that were used as station IFs. They are shown in figure 4. It is interesting observing that the spatial gradients are much lower than for yearly total precipitation (Figure 1) and that the Apennine area north to Genova has values that are comparable with those of the Apuan Alps, in spite of much lower yearly precipitation amount (about 2000mm for the former and more than $3000 \mathrm{~mm}$ for the latter). The peculiar behaviour of this area, especially of its western part, is even more evident by considering the ratios between the IFs and the corresponding total annual 
precipitation amount (figure not shown): for the western part of the study area the IF (i.e. the median of 1-day annual maxima) is more than $10 \%$ of total annual precipitation, while in the Apuan Alps it is lower than $5 \%$ (the lowest value of the whole study area).

Even though the relation between the IFs and yearly precipitation normals is rather low when the entire investigated area is considered, it becomes much higher when examined at a local scale. A large fraction of IF spatial variability can therefore be captured by a local linear regressions between the station IFs and the corresponding yearly precipitation normals. In order to estimate how large this fraction is, we compared the stations' IFs as estimated on the basis of their own data with those obtained from a local linear fit of the IF values of the neighbouring stations (excluding the station under analysis in a leave-one-out approach) versus their total annual precipitation climatological values and substituting in the equation the precipitation climatology of the station under analysis (see section 2). The results (see inset in figure 4) highlight a very good agreement between observed and reconstructed IFs, with about $95 \%$ of explained variance and a root mean square error of $7 \mathrm{~mm}$. The IFs were then estimated also for all grid-cells with the procedure described in section 2, and these values are shown in figure 4 . The grid-cell IFs have a relevant role in our procedure as they allow estimating 1-day precipitation return levels not only for the stations but also for each grid-cell.

After rescaling the 1-day annual maxima, we applied GEV to the rescaled records. The optimal pooling radius (see section 2) was estimated for each grid cell. It ranges from about 10km over northern Tuscany and eastern Liguria to about $50 \mathrm{~km}$ at the borders of the investigated area (figure not shown) were station density is generally lower, the average value being $24.4 \mathrm{~km}$. The minimum distance among stations, defined in order to increase independence among the data, turned out to be the same all over the domain, and no stations closer than $5 \mathrm{~km}$ were included in the set of pooled stations. GEV was also applied to the grid-cell records. In this case the RFA approach was not used and GEV was simply applied to any grid-point yearly 1-day maxima record.

GEV scale and shape parameters are shown in figures $5 \mathrm{a}$ and $5 \mathrm{~b}$ respectively, where the station site parameters (obtained on the bases of the single station data) are compared with the parameters obtained with the RFA approach for each grid-cell. The single station parameters are in reasonable agreement with the underlying gridded values obtained with RFA when averages over large areas are considered. However, when this comparison is performed for station sites there are remarkable differences. They are caused by rather large confidence intervals that characterize the parameter estimations. We highlight them in figures $5 \mathrm{c}$ and $5 \mathrm{~d}$ by means of the half widths of the $95 \%$ confidence intervals which were obtained both for single station record and RFA parameters with the 
maximum likelihood method (see Maugeri et al., 2015, for details). Even though RFA parameter errors are much lower than corresponding single station parameter, they are not negligible.

It is interesting to compare the RFA scale and shape parameters shown in figure 5 with those obtained with the same analysis applied by Maugeri et al. (2015) to Sicily, a region characterized by total annual precipitation which are lower than half of those observed in the present case study area. Figure 5 gives evidence that the investigated area has lower shape parameter than Sicily, which presents large areas with shape parameter higher than 0.2 and no points with negative shape parameter. Also scale parameters are generally higher in Sicily, especially in its eastern part where the 0.3 value is exceeded in large areas and the 0.4 value is reached in different points. On the other hand Sicily has lower IF values than the investigated area with only about $1 \%$ of sites exceeding the $120 \mathrm{~mm}$ threshold.

Return Levels (RLs) for 10, 50 and 100 year periods are shown in figure 6. For all return periods the highest values concern the Genoa and Apuan Alps areas. However, for longer return periods the Genoa area maximum becomes larger even than the Apuan Alps area, due to both greater scale and shaper parameter values. The effect of the scale and the shape parameters is even more evident when the RLs in figure 6 are compared with the corresponding eastern Sicily values (see figure 10 in Maugeri et al., 2015). This comparison highlights the main feature of spatial distribution of precipitation extremes in Italy. For shorter periods IF is the most important factor, whereas increasing the considered time interval, the importance of shape and scale parameters increases progressively, and areas with rather low IF as the Piana di Catania (the coastal Sicily region south of Etna mountain, between Catania and Siracusa) can have 100-year RLs higher than many areas in the region investigated in this paper. In the investigated region, therefore, rather high 1-day values (exceeding e.g. the $150 \mathrm{~mm} /$ day threshold) are recorded much more frequently than in eastern Sicily, whereas the most extreme 1-day values (exceeding e.g. the $300 \mathrm{~mm} /$ day threshold) have much more similar frequency of occurrence.

The 95\% confidence interval accompanying RFA-derived RLs was estimated too. Restricting the analysis to the gauged sites, the ratio between the upper bound of the $95 \%$ confidence interval and the central value has an average of 1.046, 1.092, and 1.115 for 10-year, 50-year, and 100-year RLs, respectively, i.e. the upper bound of the $95 \%$ confidence interval is, on average, (4.6 \pm 1.9$) \%$, $(9.2 \pm 3.7) \%$, and $(11.5 \pm 4.3) \%$ higher than the best guess.

As far as the ungauged sites are concerned, the confidence intervals become larger because the uncertainty coming from the estimation of the GEV parameters has to be combined with the 
uncertainty coming from the IF estimate (which depends on both the IF vs total annual precipitation linear fit confidence interval, and the uncertainty on the total annual precipitation climatology (see e.g. Crespi et al., 2017)), the latter being probably comparable to the former.

\subsubsection{RLs from the precipitation high-resolution daily grid}

RLs were obtained also estimating GEV parameters directly from the high-resolution grid of daily precipitation constructed for the 1951-2012 period. As expected, the interpolation method produced as a drawback a systematic overestimation of low precipitation events and an underestimation of intense events, which is even more evident in the annual maxima. This causes, therefore, an underestimation of RLs which characterizes almost the whole area. The mean value of RLs decrease of $-15.4 \%$ (from about $120 \mathrm{~mm} /$ day to about $102 \mathrm{~mm} /$ day), with an interquartile distance of $6.8 \%$, for 10-year RLs; of $-17.7 \%$ (from about $167 \mathrm{~mm} /$ day to about $137 \mathrm{~mm} /$ day), with an interquartile distance of $9.8 \%$ for 50 -year RLs; and of $-18.5 \%$ (from about $189 \mathrm{~mm} /$ day to about $154 \mathrm{~mm} /$ day), with an interquartile distance of $11.9 \%$.

\section{Conclusions}

A data set of 371 quality-checked and homogenized daily precipitation records has been set up for an area which is very prone to severe floods, including eastern Liguria and northern Tuscany. It has been used to extract records of yearly 1-day precipitation maxima to investigate extreme precipitation by means of the GEV distribution, estimated with a RFA approach for each point of a 30 arc-second resolution grid covering the examined area.

The main results to be highlighted are as follows.

i. 1-day annual precipitation maxima present no significant trends over the examined area and over the period covered by the data.

ii. RFA proved to be a very effective method to reduce the confidence interval of GEV parameters and RLs, but some care must be taken to preserve both conditions of identically distributed data and independence among events.

iii. A local linear regression of the station IF versus their mean annual precipitation totals allowed to estimate the IF on a high-resolution grid. This allowed RLs to be estimated at a high resolution not 
only as normalized values, but also in absolute values. Therefore, the methodology presented in the paper turns out to be an operational tool to assess precipitation risk estimates.

iv. Both GEV parameters and corresponding RLs exhibit important spatial gradients over the area, the differences being driven both by the scale and the shape parameters.

v. A comparison of the present paper results, focused on a very wet area of northern Italy, with those obtained for a drier region of southern Italy (Sicily region) highlighted the important role of scale and shape parameters, more than the total annual precipitation, in defining the magnitude of extreme events.

vi. The high-resolution maps of absolute values of RL10, RL50 and RL100 show that the area north of Genoa and that of the Apuan Alps emerge as those most affected by extreme precipitations with the highest 100-year RLs (more than $400 \mathrm{~mm}$ ), even if they are characterized by very different total annual precipitation amounts (about $2000 \mathrm{~mm}$ for the area north of Genoa and more than $3000 \mathrm{~mm}$ for the Apuan Alps), testifying the relevance of scale and shape parameters, which are among the largest for the area of Genoa and among the lowest values of the region for the Apuan Alps.

vii. The same analysis applied to a gridded version of the daily precipitation data-set without a RFA highlighted an important drawback typical of any interpolation method, i.e. the underestimation of intense events which is magnified in the analysis of annual maxima.

This climatological investigation may provide important clues for the estimation of possible ground effects of extreme events, allowing a better understanding of the cause-effect relationships between intense rainfall and instability processes, which is crucial for hazard assessment at different spatial and temporal scales in changing environments (Soldati et al., 2006; Benito and Hudson, 2010; Goudie, 2010; Borgatti and Soldati, 2013). Nowadays, we are not only observing climate changes, but also modifications of environmental climate-related variables which need in-depth investigation. At the same time, society is changing with growing needs and higher vulnerability. Evidence from the recent past calls for an increase in flood and landslide activity, but generalization is not possible so far. However, the output of such studies are likely to facilitate the assessment of flood and landslide risks whose effects may determine high costs for the communities, as shown by the recent disasters that have affected the investigated regions of Liguria and Tuscany (Galve et al., 2016) as well as other regions of Europe. 


\section{Aknowledgements}

We sincerely thank all the institutions that allowed access to the data for research purposes and contributed to set up the daily precipitation database. They are (most of the data are available online from the specified web sites, some other data have to be requested to the mentioned institutions): Regional Environmental Agency of Liguria (ARPA Liguria, https://www.arpal.gov.it/), Regional Hydrographic Service of Tuscany (SIR Toscana, http://www.sir.toscana.it/), Regional Environmental Agency of Emilia-Romagna (ARPAE, https://www.arpae.it/), Regional Environmental Agency of Piedmont (ARPA Piemonte) and Regional Environmental Agency of Lombardy (ARPA Lombardia, http://www.arpalombardia.it/).

Part of this work was supported by the Special Project HR-CIMA within the frame of the Project of National Interest NextData.

\section{References}

Alila, Y.: A hierarchical approach for the regionalization of precipitation annual maxima in Canada. J. Geophys. Res. 104 (D24), 31, 645-655, 1990.

Alpert, P., Ben-Gai, T., Baharad, A., Benjamini, Y., Yekutieli, D., Colacino, M., Diodato, L., Ramis, C., Homar, V., Romero, R., Michaelides, S., and Manes, A.: The paradoxical increase of Mediterranean extreme daily rainfall in spite of decrease in total values. Geophys. Res. Lett., 29, 311-31-4, doi:10.1029/2001GL013554, 2002.

Antolini G., L. Auteri, V. Pavan, F. Tomei, R. Tomozeiua, V. Marletto. A daily high-resolution gridded climatic data set for Emilia-Romagna, Italy, during 1961-2010. International Journal of Climatology, 36, 1970-1986, doi: 10.1002/joc.4473, 2015.

Arnone, E., Pumo, D., Viola, F., Noto, L. V., and La Loggia, G.: Rainfall statistics changes in Sicily, Hydrol. Earth Syst. Sci., 17, 2449-2458, https://doi.org/10.5194/hess-17-2449-2013, 2013.

Benito, G. and Hudson, P. F.: Flood hazards: the context of fluvial geomorphology. In: I. AlcántaraAyala, I., Goudie, A.S. (eds.), Geomorphological Hazards and Disaster Prevention. Cambridge University Press, Cambridge, 111-128, 2010. 
Bertolini, A.: Realization of a high-resolution gridded precipitation data set for the study of the effects of extreme events on slope instability, Ph.D. thesis (Course in Models and Methods for Material and Environmental Sciences), Università degli Studi di Modena e Reggio Emilia, 2017.

Borgatti, L. and Soldati, M.: Hillslope Processes and Climate Change. In: Shroder, J.F., Marston, R.A., Stoffel, M. (eds.), Treatise on Geomorphology, Vol. 7, Mountain and Hillslope Geomorphology. Academic Press, San Diego, 306-319, 2013.

Brath A., Franchin M. and Galeati G., Valutazione delle piogge intense nell'Italia centrosettentrionale, L'ACQUA, 4, 15-27, 1998.

Brath, A. and Castellarin, A.: Tecniche di affinamento delle previsioni regionali del rischio pluviometrico (in Italian), Proceedings of the scientific seminar La progettazione della difesa idraulica - Interventi di laminazione controllata delle piene fluviali, edited by: Maione, U., Brath, A., and Mignosa, P., BIOS (Cosenza), 93-121, 2001.

Brath, A., Castellarin, A., and Montanari, A.: Assessing the reliability of regional depth-durationfrequency equations for gaged and ungaged sites, Water Resour. Res., 39(12), 1367-1379, 2003.

Brunet, M., Sigró, J., Jones, P. D., Saladié, O., Aguilar, E., Moberg, A., Lister, D., and Walther, A.: Long-term changes in extreme temperatures and precipitation in Spain, Contributions to Science, 3, 331-342, doi:10.2436/20.7010.01.11, 2007.

Brunetti, M., Colacino, M., Maugeri, M., and Nanni, T.: Trends in the daily intensity of precipitation in Italy from 1951 to 1996, Int. J. Climatol., 21, 299-316, doi:10.1002:joc.613, 2001.

Brunetti, M., Maugeri, M., Monti, F., and Nanni, T.: Changes in daily precipitation frequency and distribution in Italy over the last 120 years. J. Geophys. Res., 109, D05102, doi:10.1029/2003JD004296, 2004.

Brunetti M., M. Maugeri, F. Monti, T. Nanni: Temperature and precipitation variability in Italy in the last two centuries from homogenized instrumental time series. International Journal of Climatology, 26, 345-381, 2006.

Brunetti, M., Caloiero, T., Coscarelli, R., Gullà, G., Nanni, T., and Simolo, C.: Precipitation variability and change in the Calabria region (Italy) from high resolution daily dataset, Int. J. Climatol., 32, 57-73, doi:10.1002/joc.2233, 2012. 
Brugnara, Y., Brunetti, M., Maugeri, M., Nanni T., and Simolo, C.: High-resolution analysis of daily precipitation trends in the central Alps over the last century, Int. J. Climatol., 32, 1406-1422, doi:10.1002/joc.2363, 2012.

Buzzi A., S. Davolio, P. Malguzzi, O. Drofa, and D. Mastrangelo. Heavy rainfall episodes over Liguria in autumn 2011: numerical forecasting experiments, Nat. Hazards Earth Syst. Sci., 14, 13251340, doi:10.5194/nhess-14-1325-2014, 2014.

Cacciamani C., D. Cesari, F. Grazzini, T. Paccagnella, M. Pantone. Mesoscale Data Assimilation Experiments in a case study of intense precipitation occurred in central Italy: the Versilia Flood Of June 1996. MAP newsletter, $N^{\circ}$ 7, Ottobre 1997; Editor: MAP Newsletter, Swiss Meteorological Institute, CH-8044 Zurigo, 1997.

Cannarozzo, M., D’Asaro, F., and Ferro, V.: Regional rainfall and flood frequency analysis for Sicily using the two component extreme value distribution, Hydrolog. Sci. J., 40, 19-41, 1995.

Castellarin A:, D.H. Burn, A. Brath: Assessing the effectiveness of hydrological similarity measures for flood frequency analysis, Journal of Hydrology 241, 270-285, 2001

Castellarin A., D.H. Burn, A. Brath: Homogeneity testing: How homogeneous do heterogeneous cross-correlated regions seem?, Journal of Hydrology 360, 67-76, 2008.

Coles, S.: An introduction to statistical modeling of extreme values, Springer, London, UK, 208 pp., 2001.

Craddock, J. M.: Methods of comparing annual rainfall records for climatic purposes, Weather, 34, 332-346, 1979.

Crespi A., M. Brunetti, G. Lentini, M. Maugeri: 1961-1990 high-resolution monthly precipitation climatologies for Italy, International Journal of Climatology, in press, doi: 10.1002/joc.5217, 2017.

Crisci A., Gozzini B., Meneguzzo F., Pagliara S. and Maracchi G.: Extreme rainfall in a changing climate: regional analysis and hydrological implications in Tuscany, Hydrological Processes, 16, 1261-1274, 2002.

D’Asaro F., Grillone G.: Regional frequency analysis for extreme rainfall in Sicily. Journal of Agricultural Engineering, 1, 11-23, 2008. 
Davison, A. C. and Smith, R. L.: Models for exceedances over high thresholds, J. Roy. Stat. Soc. B, $52,393-442,1990$.

Davolio S., Silvestro F., Malguzzi P. Effects of Increasing Horizontal Resolution in a Convection Permitting Model on Flood Forecasting: The 2011 Dramatic Events in Liguria (Italy). Journal of Hydrometeorology, 16, 1843-1856, 2015.

Di Luzio, M. and Johnson, G. L. and Daly, C. and Eischeid, J. K. and Arnold, J. G. Constructing Retrospective Gridded Daily Precipitation and Temperature Datasets for the Conterminous United States, Journal of Applied Meteorology and Climatology, 47, 475-497, 2008.

Faccini, F., Piccazzo, M., and Robbiano, A.: Natural hazards in San Fruttuoso of Camogli (Portofino Park, Italy): a case study of a debris flow in a coastal environment, Bollettino della Societa Geologica Italiana, 128, 641-654, 2009.

Faccini, F., Paliaga, G., Piana, P., Sacchini, A., Watkins, C.: The Bisagno stream catchment (Genoa, Italy) and its major floods: geomorphic and land use variations in the last three centuries, Geomorphology, 273, 14-27, 2016.

Fiori, E., Comellas, A., Molini, L., Rebora, N., Siccardi, F., Gochis, D. J., Tanelli, S., and Parodi, A.: Analysis and hindcast simulations of an extreme rainfall event in the Mediterranean area: The Genoa 2011 case, Atmos. Res., 138, 13-29, 2014.

Fiori, E., Ferraris, L., Molini, L., Siccardi, F., Kranzlmueller, D., and Parodi, A.: Triggering and evolution of a deep convective system in the Mediterranean Sea: modelling and observations at a very fine scale, Q. J. Roy. Meteor. Soc., 143, 927-941, doi:10.1002/qj.2977, 2017.

Franchini, M. and Galeati, G.: La regionalizzazione delle piogge intense mediante il modello TCEV. Una applicazione alla regione Romagna-Marche (in Italian), Idrotecnica, 5, 1994.

Galve, J.P., Cevasco, A., Brandolini, P., Soldati M.: Assessment of shallow landslide risk mitigation measures based on land use planning through probabilistic modelling, Landslides, 12(1), 101-114, 2015.

Galve, J.P., Cevasco, A., Brandolini, P., Piacentini, D., Azañón, J.M., Notti, D., Soldati, M.: Costbased analysis of mitigation measures for shallow-landslide risk reduction strategies, Engineering Geology, 213, 142-157, 2016. 
Gallus, W.A., Parodi, A. and Maugeri, M.: Possible Impacts of a Changing Climate on Intense Ligurian Sea Rainfall Events, Int. J. Climatol., published online, DOI: 10.1002/joc.5372, 2017.

Giorgi. F., Lionello, P.: Climate change projections for the Mediterranean region, Global and Planetary Change, 63, 90-104, 2008.

Goudie, A.S.: Geomorphological hazards and global climate change. In: Alcantara-Ayala, I., Goudie, A.S. (eds.), Geomorphological Hazards and Disaster Prevention. Cambridge University Press, Cambridge, pp. 245-256, 2010.

Hosking, J. R. M. and Wallis, J. R.: The effect of intersite dependence on regional flood frequency analysis, Water Resour. Res., 244, 588-600, 1988.

Katz, R. W., Parlange, M. B., and Naveau, P.: Statistics of extremes in hydrology, Adv. Water Resour., 25, 1287-1304, 2002.

Kioutsioukis, I., Melas, D., and Zerefos, C.: Statistical assessment of changes in climate extremes over Greece. Int. J. Climatol., 30, 1723-1737, doi:10.1002/joc.2030, 2010.

Kostopoulou, E. and Jones, P. D.: Assessment of climate extremes in the eastern Mediterranean, Meteorol. Atmos. Phys., 89, 69-85, doi:10.1007/s00703-005-0122-2, 2005.

Kumar P. V., Bindi M., Crisci A., Maracchi G.: Detection of variations in precipitation at different time scales of twentieth century at three locations of Italy, Weather and Climate Extremes, 2, 7-15, https://doi.org/10.1016/j.wace.2013.10.005, 2013.

Madsen, H. and Rosbjerg, D.: The partial duration series method in regional index-flood modeling,Water Resour. Res., 33, 737-746, doi:10.1029/96WR03847, 1997.

Madsen, H., Rasmussen, P. F., and Rosbjerg, D.: Comparison of annual maximum series and partial duration series methods for modeling extreme hydrologic events: 1. At-site modeling, Water Resour. Res., 33, 747-757, doi:10.1029/96WR03848, 1997.

Martins, E. S. and Stedinger, J. R.: Generalized maximum likelihood generalized extreme-value quantile estimators for hydrologic data, Water Resour. Res., 36, 737-744, doi:10.1029/1999WR900330, 2000. 
Maugeri M., M. Brunetti, M. Garzoglio, C. Simolo: High-resolution analysis of 1-day extreme precipitation in Sicily, Natural Hazards and Earth System Sciences, 15, 2347-2358, 2015.

Mazzoni, G.B., Olivieri, M. and M. Ratti, L'evento alluvionale del 19 Giugno 1996 in Alta Versilia. Nimbus, Società Meteorologica Subalpina, Torino (Italy), 13-14, 136-140, 1997.

Moberg, A., Jones, P. D., Lister, D. et al.: Indices for daily temperature and precipitation extremes in Europe analysed for the period 1901-2000, J. Geophys. Res., 111, D22106, doi:10.1029/2006JD007103, 2006.

Parodi, A., Ferraris, L., Gallus, W., Maugeri, M., Molini, L., Siccardi, F., and Boni, G.: Ensemble cloud-resolving modelling of a historic back-building mesoscale convective system over Liguria: the San Fruttuoso case of 1915, Clim. Past, 13, 455-472, https://doi.org/10.5194/cp-13-455-2017, 2017.

Piccarreta M., Pasini A., Capolongoa D. and Lazzari M.: Changes in daily precipitation extremes in the Mediterranean from 1951 to 2010: the Basilicata region, southern Italy, International Journal of Climatology, 33, 3229-3248, doi: 10.1002/joc.3670, 2013.

Rebora N., Molini L., Casella E., Comellas A., Fiori E., Pignone F., Siccardi F., Silvestro F., Tanelli S., Parodi A. Extreme Rainfall in the Mediterranean: What Can We Learn from Observations? Journal of Hydrometeorology, 14, 906-922, 2013.

Rodrigo, F. S.: Changes in the probability of extreme daily precipitation observed from 1951 to 2002 in the Iberian Peninsula, Int. J. Climatol., 30, 1512-1525. doi:10.1002/joc.1987, 2010.

Rossi, F., Fiorentino, M., and Versace P.: Two Component Extreme Value Distribution for flood frequency analysis, Water Resources Research, 20, 847-856, doi:10.1029/WR020i007p00847, 1984.

Saidi H., Ciampittiello M., Dresti C., Ghiglieri G.: Assessment of Trends in Extreme Precipitation Events: A Case Study in Piedmont (North-West Italy), Water Resources Management, 29, 63-80, 2015.

Schaefer, M.G.: Regional analysis of precipitation annual maxima in Washington State. Water Resour. Res. 26 (1), 131-191, 1990.

Soldati, M., Borgatti, L., Cavallin, A., De Amicis, M., Frigerio, S., Giardino, M., Mortara, G., Pellegrini, G.B., Ravazzi, C., Tellini, C., Zanchi, A. in coll. with Alberto, W., Albanese, D., Chelli, A., Corsini, A., Marchetti, M., Palomba, M., Panizza, M., Geomorphological evolution of slopes and 
climate changes in northern Italy during the Late Quaternary: spatial and temporal distribution of landslides and landscape sensitivity implications, Geografia Fisica e Dinamica Quaternaria, 29(2), 165-183, 2006.

Toreti, A., Xoplaki, E., Maraun, D., Kuglitsch, F. G., Wanner, H., and Luterbacher, J.: Characterisation of extreme winter precipitation in Mediterranean coastal sites and associated anomalous atmospheric circulation patterns, Nat. Hazards Earth Syst. Sci., 10, 1037-1050, doi:10.5194/nhess-10-1037-2010, 2010.

Ulbrich, U., Lionello, P., Belušic, D., Jacobeit, J., Knippertz, P., Kuglitsch, F. G., Leckebusch, G. C., Luterbacher, J., Maugeri, M., Maheras, P., Nissen, K. M., Pavan, V., Pinto, J. G., Saaroni, H., Seubert, S., Toreti, A., Xoplaki, E., and Ziv, B.: Chapter 5. Climate of the Mediterranean: Synoptic Patterns, Temperature, Precipitation, Winds, and Their Extremes, in: The Climate of the Mediterranean Region From the Past to the Future, edited by: Lionello, P., Elsevier, London, UK, ISBN: 978-0-12-4160422, 301-346, 2012.

van den Besselaar, E. J. M., Klein Tank, A. M. G., and Buishand, T. A.: Trends in European precipitation extremes over 1951-2010, Int. J. Climatol. 33, 2682-2689, doi:10.1002/joc.3619, 2013.

\section{Figure captions}

Fig. 1 - Study area and spatial distribution of 1961-1990 yearly precipitation normals. The inset shows the position of the study area within northern Italy and the station sites. Large red dots indicate stations used for GEV analyses. The other stations (small white dots) were used only for quality check and homogenisation procedures and to get the daily 1951-2012 daily precipitation fields.

Fig. 2 - Panels a-e: stations and gridded precipitation for the events listed in the introduction that fall within the period covered by the daily precipitation grid. Panel f: absolute 1-day maxima at each station and grid point.

Fig. 3 - Trend slopes of the 371 yearly station series of 1-day precipitation maxima relative to the full record period (left) and the sub-period with best data availability (right). Red symbols denote significant trends ( $\mathrm{p}$ value $<0.05$ ) according to a Mann-Kendall test.

Fig. 4 - Station and grid-point IFs. The inset shows the agreement of the station IFs with the corresponding values we obtained from yearly precipitation normals, taking advantage of the fact that 
at small spatial scale station IFs exhibit a very high correlation with the corresponding yearly precipitation normals.

Fig. 5 - Panels a-b: Dots: spatial distribution of (a) the scale (IF units) and (b) the shape parameters for single station records. Gridded fields: spatial distribution of (a) the scale (IF units) and (b) the shape parameters obtained by means of the RFA approach. Panels c-d: half widths of the 95 percent confidence intervals of the parameter estimations in panels a-b.

Fig. 6 - Grid-point 10-, 50-, and 100-year RLs, expressed as absolute precipitation amounts (mm/day). 
Figures

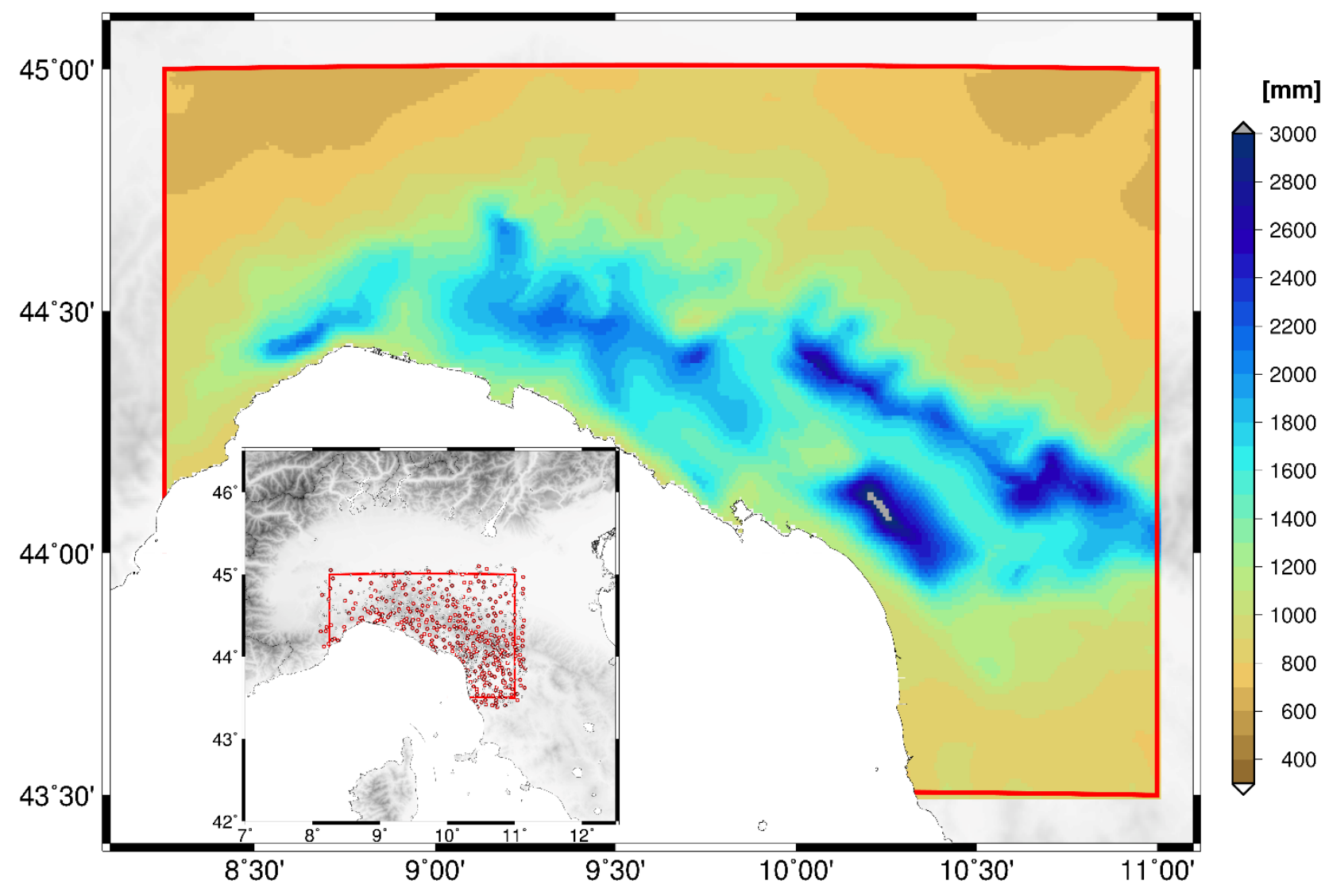

Figure 1. 

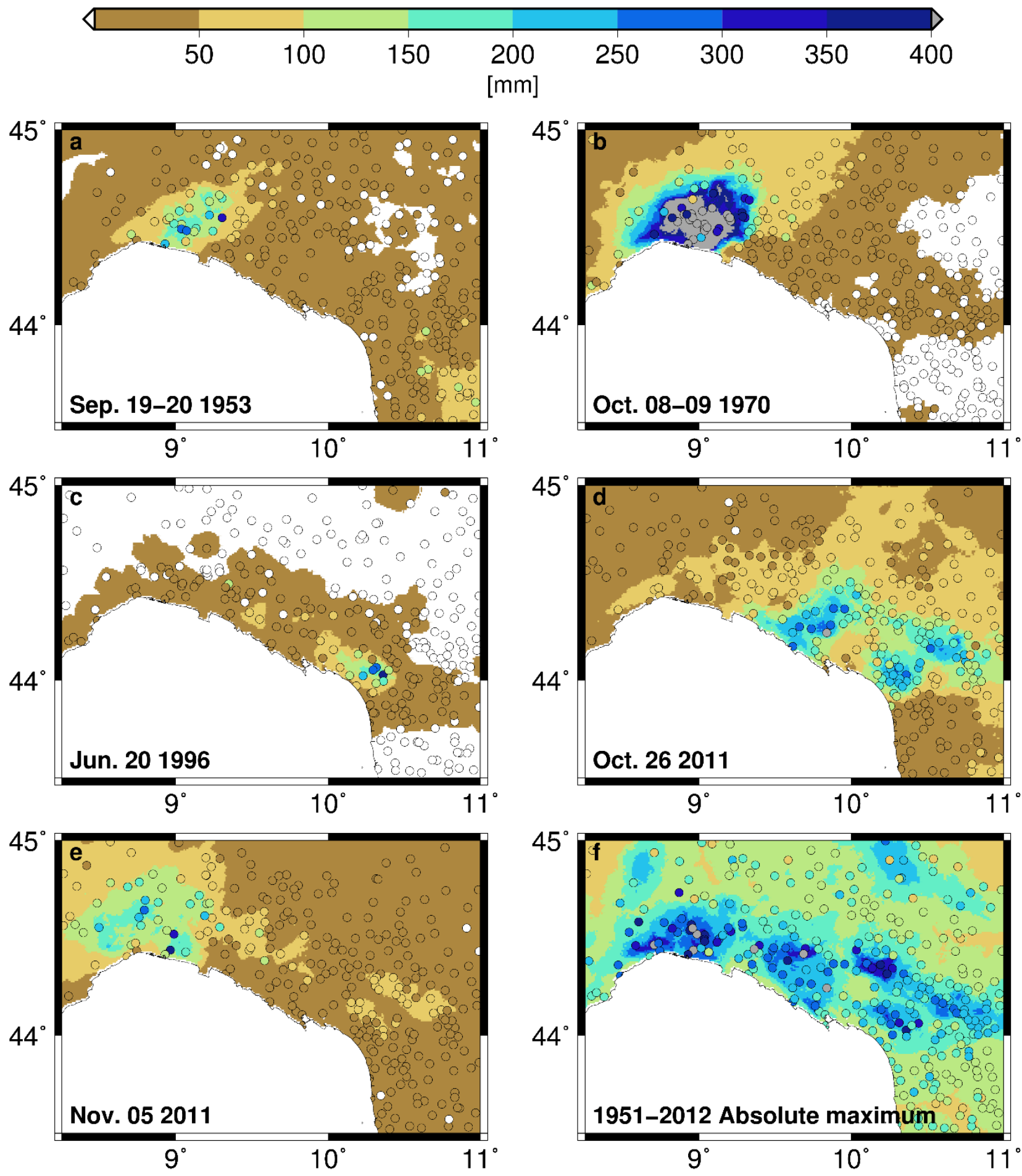

Figure 2. 

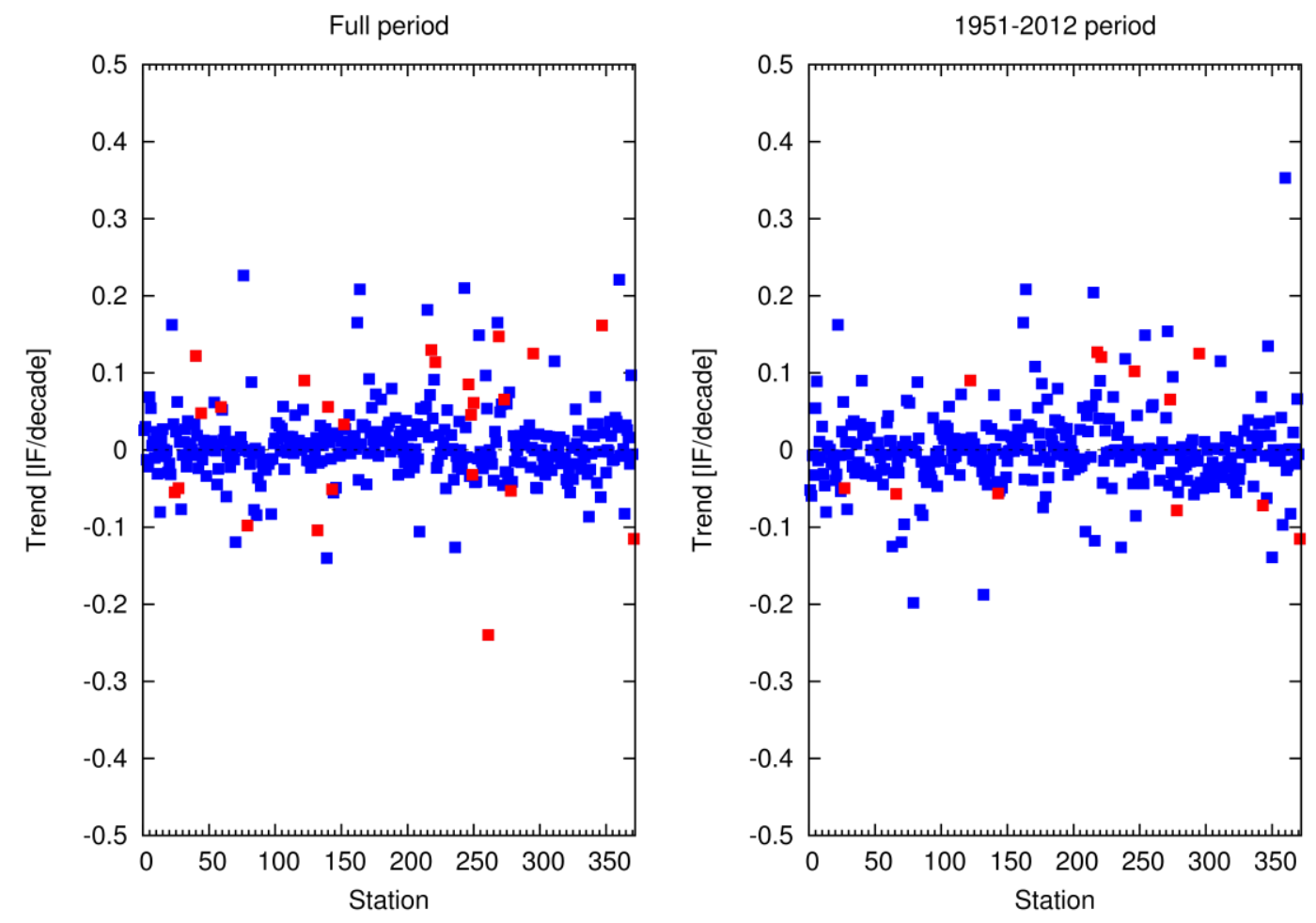

Figure 3. 


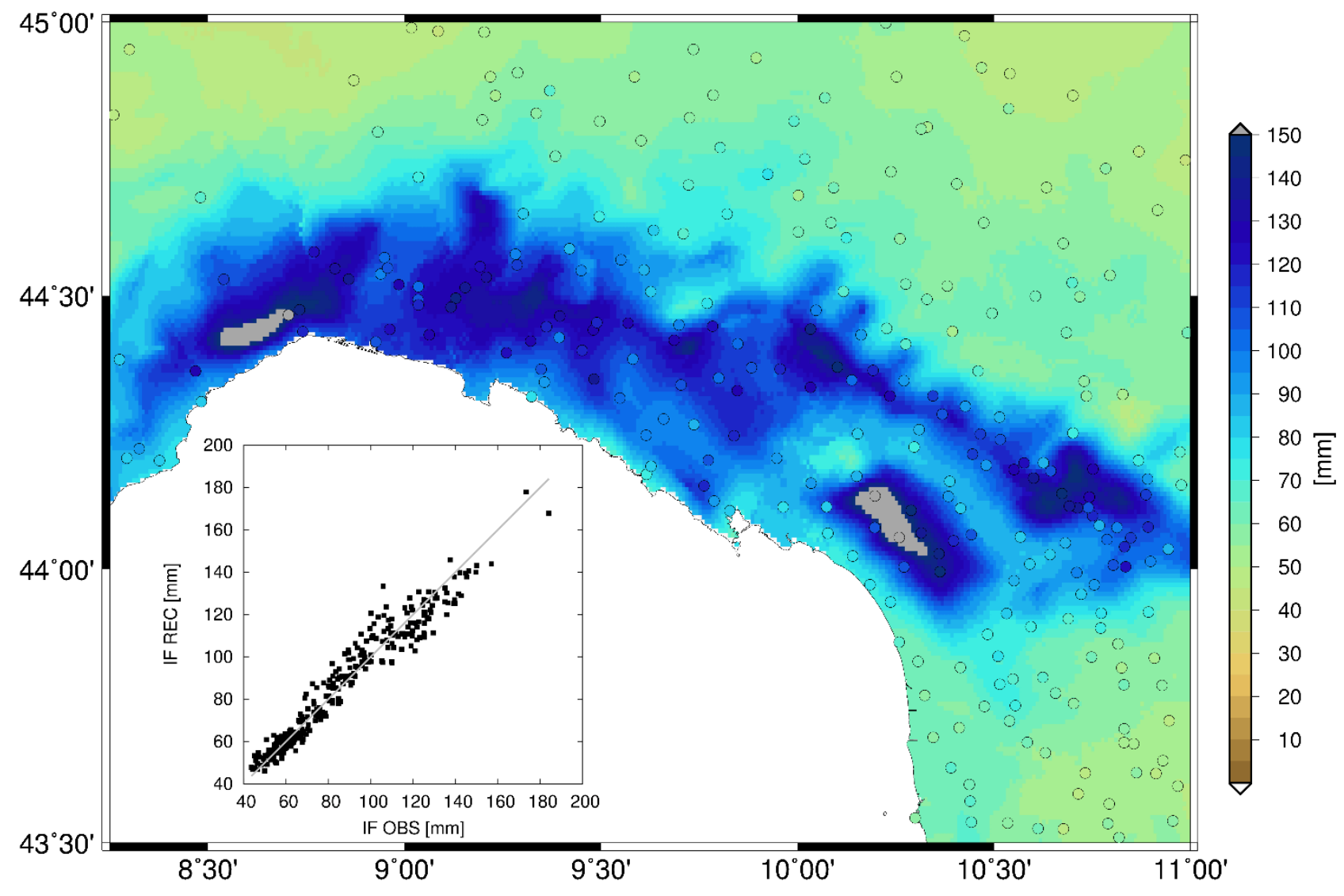

Figure 4. 

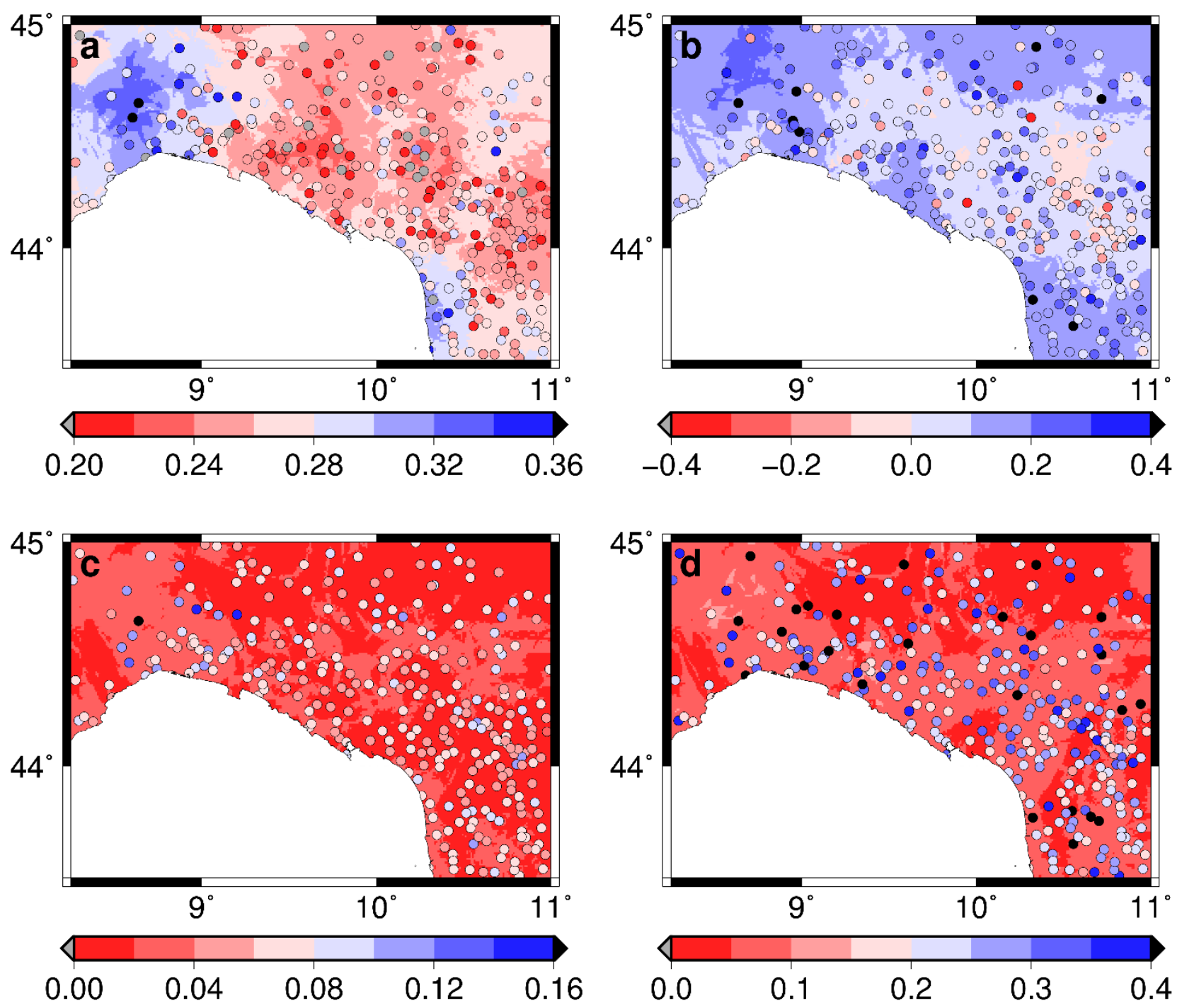

Figure 5. 


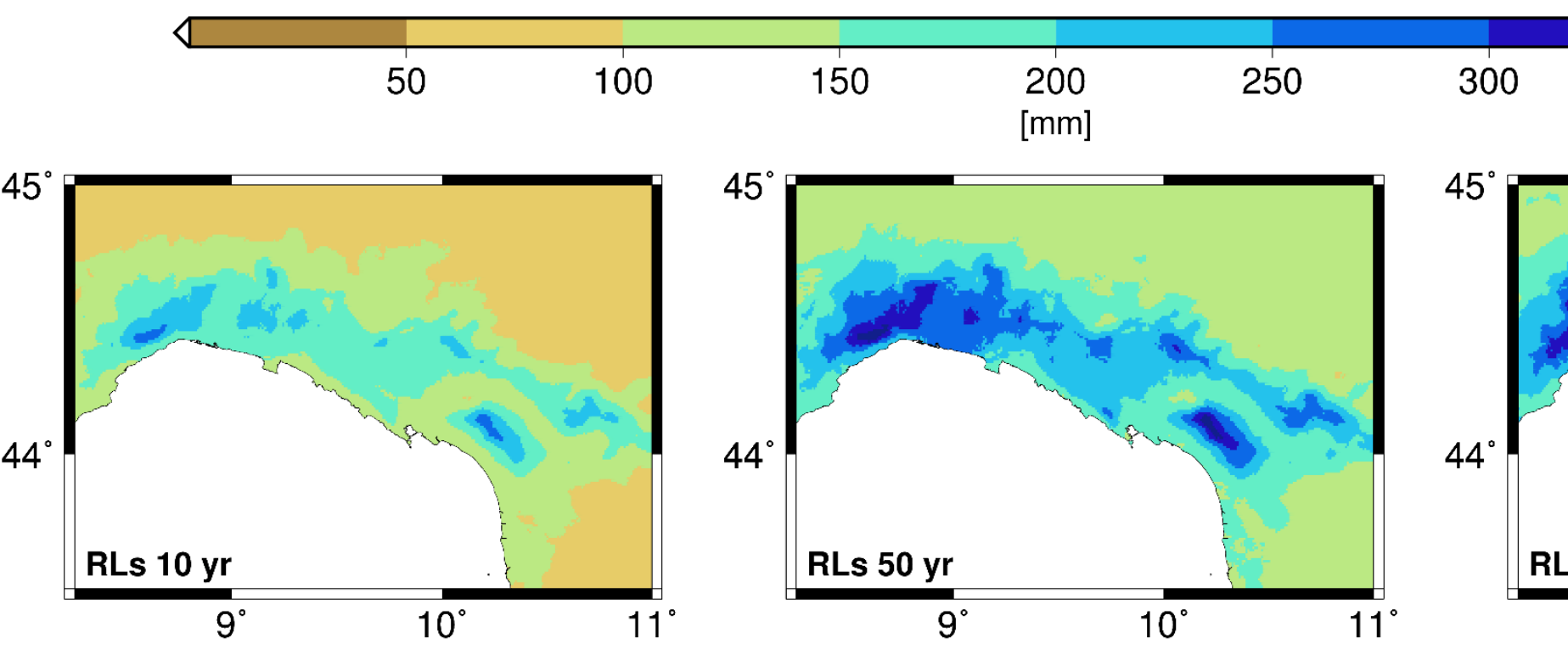

Figure 6. 